\title{
Experimental Study to Improve the Tribological Behaviors of M50 Steel via WS 2 Solid Lubricant under High Temperatures
}

\author{
Essa FA ${ }^{1,2 *}$, Jingui Yu ${ }^{1 *}$, Qiaoxin $\mathrm{Zhang}^{1}$ and Xingjiu Huang ${ }^{1}$ \\ ${ }^{1}$ School of Mechanical and Electronic Engineering,, China \\ ${ }^{2}$ Department of Mechanical Engineering, Egypt
}

*Corresponding author: Essa FA, School of Mechanical and Electronic Engineering, Wuhan 430070, China,

Jingui Yu, Mechanical Engineering Department, Kafrelsheikh, Egypt,

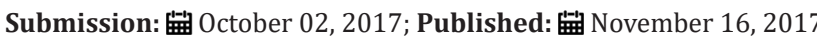

\begin{abstract}
An experimental investigation is conducted to improve the tribological properties of M50 composites (M). Using WS (MW) is investigated under different temperatures (RT, 200, 400, 600, and $\left.800^{\circ} \mathrm{C}\right)$, and constant applied load $(12 \mathrm{~N})$ and sliding speed $(0.2 \mathrm{~m} / \mathrm{s})$. The XRD, EPMA, FESEM, and EDS Mapping are conducted to understand the major mechanisms leading to improve the tribological properties of the M50 composites. Results suggested that MW provides the best tribological behaviors over the wide temperature range. The friction coefficients of MW are decreased by $13.51 \%$ as compared to that of $\mathrm{M}$ at $800^{\circ} \mathrm{C}$ due to the formation of lubricating tribo-films on the worn surfaces.
\end{abstract}

Keywords: Tungsten disulfide; M50 steel; Friction; Composite; Solid lubricant

\section{Introduction}

The demand for self-lubricating composites has been driven by the advanced technological systems like high-performance gas turbine engines and aerospace applications in which the working components are supposed to possess lower friction coefficients and better wear resistance over a wide temperature range [14]. The urgent need to improve the performance of bearings in aerospace and biomedical systems has attracted the researcher attention to find out self-lubricating materials leading the systems to achieve augmented performance in challenging surroundings. The bearings in aerospace and biomedical systems are fabricated mainly from M50 steel due to its high strength, toughness, contact fatigue resistance, and hardness [5-7]. However, their practical applications as relative sliding components at high temperatures have been restricted by their poor properties of anti-friction and wear-resistance. Through the experiments that carried out by Rosado et al. [8-11] to investigate the effect of temperature (RT and $177^{\circ} \mathrm{C}$ ) on the wear behavior of M50 steel when using different lubricants, they confirmed that the temperature and lubricant type affect significantly the wear and friction of M50. Childs and Mimaroglu [12] attempted experimentally to reduce the friction and wear of dry and lubricated M50 and T1 high speed steels and silicon nitrides by testing them at high temperatures were ranged from 20 to $600{ }^{\circ} \mathrm{C}$ or $200{ }^{\circ} \mathrm{C}$.
As reviewed by Sliney, graphite, molybdenum disulfide and silver will lose lubricating function at high temperatures due to their inadequate oxidation resistance [13]. High temperature lubricants, such as $\mathrm{CuO}$ and $\mathrm{BaF}_{2}$, are unacceptable for application below $500{ }^{\circ} \mathrm{C}$ due to their intrinsic nature [14]. During the recent decades, researcher had developed the coatings and self-lubricating materials that contain solid lubricants. At the temperatures below $500{ }^{\circ} \mathrm{C}$, the traditional lubricants comprising the soft metals, graphite, transition metal dichalcogenides (e.g. molybdenum and tungsten disulfides, diselenides, and ditellurides), and polymers (i.e. polytetrafluoroethylene, polyimides) are good lubricants. On the other hand, the fluorides $\left(\mathrm{CaF}_{2}, \mathrm{BaF}_{2}, \mathrm{CeF}_{2}, \mathrm{LaF}_{3}\right.$ ), oxides (e.g. $\mathrm{ZnO}, \mathrm{PbO}, \mathrm{CuO}, \mathrm{B}_{2} \mathrm{O}_{3}, \mathrm{ReO}_{2}$ ), sulfates (e.g. $\mathrm{CaSO}_{4}, \mathrm{BaSO}_{4}, \mathrm{SrSO}_{4}$ ), and the mixture of some of them are the lubricants of high temperatures $\left(>500^{\circ} \mathrm{C}\right)$ as stated and explained by Yang et al. [15].

It is well known that tungsten disulfide $\left(\mathrm{WS}_{2}\right)$, being one of transition metal dichalcogenides, has been extensively used as a solid lubricant because of its lamellar structure [16,17]. The tribological behavior of wear and friction coefficient for the thin

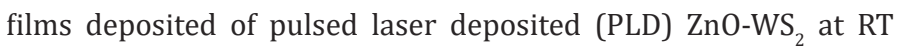
was investigated by Prasad et al. [18]. In another study for Walck et al. [19], the effects of temperature $(400,500,600,700$ and 800 ${ }^{\circ} \mathrm{C}$ ) on the lubricious characteristics of $\mathrm{ZnO}-\mathrm{WS}_{2}$ were investigated. 
All previous articles confirmed that $\mathrm{ZnO}-\mathrm{WS}_{2}$ is a good lubricative candidate at elevated temperatures.

The main aim of this present study is to investigate the effect of temperature from room temperature (RT, $27^{\circ} \mathrm{C}$ ) to $800{ }^{\circ} \mathrm{C}$ on the tribological characteristics of M50 steel composites when using $\mathrm{WS}_{2}$ as a solid lubricant and sliding against $\mathrm{Si}_{3} \mathrm{~N}_{4}$ counterface. The sliding wear mechanisms are explored and explained in details. The corresponding results help to provide more information for using M50 matrix composites.

\section{Experimental Details}

\section{Specimens' Preparation and Fabrication}

Table 1: Chemical composition of M50 (wt.\%).

\begin{tabular}{|c|c|c|c|c|c|c|c|c|}
\hline $\mathbf{C}$ & $\mathbf{M n}$ & $\mathbf{S i}$ & $\mathbf{C r}$ & $\mathbf{M o}$ & $\mathbf{N i}$ & $\mathbf{V}$ & $\mathbf{C u}$ & $\mathbf{F e}$ \\
\hline 0.72 & 0.30 & 0.20 & 3.72 & 4.00 & 0.10 & 1.00 & 0.05 & Balance \\
\hline
\end{tabular}

The starting individual materials for the tested samples, which are shown with compositions in Table 1, have an average particle size of $35-65 \mu \mathrm{m}$ and $99.9 \mathrm{wt}$. \% in purity. The starting powders were mixed by vibration milling and then the mixed powders were enclosed in a graphite die and sintered by spark plasma sintering, SPS machine with a D.R.Sinter® SPS3.20 (Sumitomo Coal \& Mining, now SPS Syntex Inc.), in pure Ar atmosphere protection. A heating rate of $100{ }^{\circ} \mathrm{C} \mathrm{min}^{-1}$ was programmed. The sintering temperature was $1000{ }^{\circ} \mathrm{C}$. The holding time at $1000{ }^{\circ} \mathrm{C}$ was $5 \mathrm{~min}$. The holding pressure at $1000{ }^{\circ} \mathrm{C}$ was $35 \mathrm{MPa}$. Finally, the as-prepared samples were polished with metallographic abrasive paper to make the following analyses and tests.

\section{Vickers' Hardness and Density}

Based on the ASTM standard E92-82 [20], for each as-prepared specimen, micro- hardness was measured using a HVS-1000
Vickers' hardness instrument. A load weight of $1000 \mathrm{~g}$ was applied to perform the indentation and maintained for $10 \mathrm{~s}$. Ten locations were randomly chosen to test and the average of all the ten readings was taken as micro hardness of the sample, as listed in Table 2. Furthermore, the densities of the samples were measured based on Archimedes principles and according to the ASTM Standard B96208 [21]. Similarly, the average value of three experimental tests of density is obtained for every sample.

Table 2: Compositions and hardness of the sintered M50 matrix composites.

\begin{tabular}{|c|c|c|}
\hline Sample & Compositions (wt.\%) & Hardness (HV1) \\
\hline M & M50+0.0\%WS $_{2}$ & $402.5 \pm 0.079$ \\
\hline MW & M50+10.0\%W S $_{2}$ & $460.4 \pm 0.088$ \\
\hline
\end{tabular}

\section{Tribological Experiments}

A HT-1000 ball-on-disk high temperature tribometer was used to evaluate the tribological properties of composites as shown in Figure 1 . The disk with a size of $\varnothing 20 \mathrm{~mm} \times 6 \mathrm{~mm}$, which was the asprepared composite. The counterpart ball with a diameter of $6 \mathrm{~mm}$ was made of $\mathrm{Si}_{3} \mathrm{~N}_{4}$ ceramic (16.7GPa, surface roughness (Ra) of $0.01 \mu \mathrm{m})$. Prior tocommencing test, the disks and counterpart balls were ultrasonically cleaned with acetone, and then thoroughly dried in hot air. The test temperatures were selected to be 25,200 , 400, 600 and $800{ }^{\circ} \mathrm{C}$. The wear test parameters were: $10 \mathrm{~N}$ load, $0.2 \mathrm{~ms}^{-1}$ speed, radius of wear track $2 \mathrm{~mm}$ and $40 \mathrm{~min}$ testing time for the different temperatures. At $25{ }^{\circ} \mathrm{C}$, friction and wear tests were performed in air with a relative humidity of $20 \pm 5 \%$. For elevated temperature friction and wear tests, as-prepared composites were fixed in a furnace and were heated to the required temperature before the start of tests.

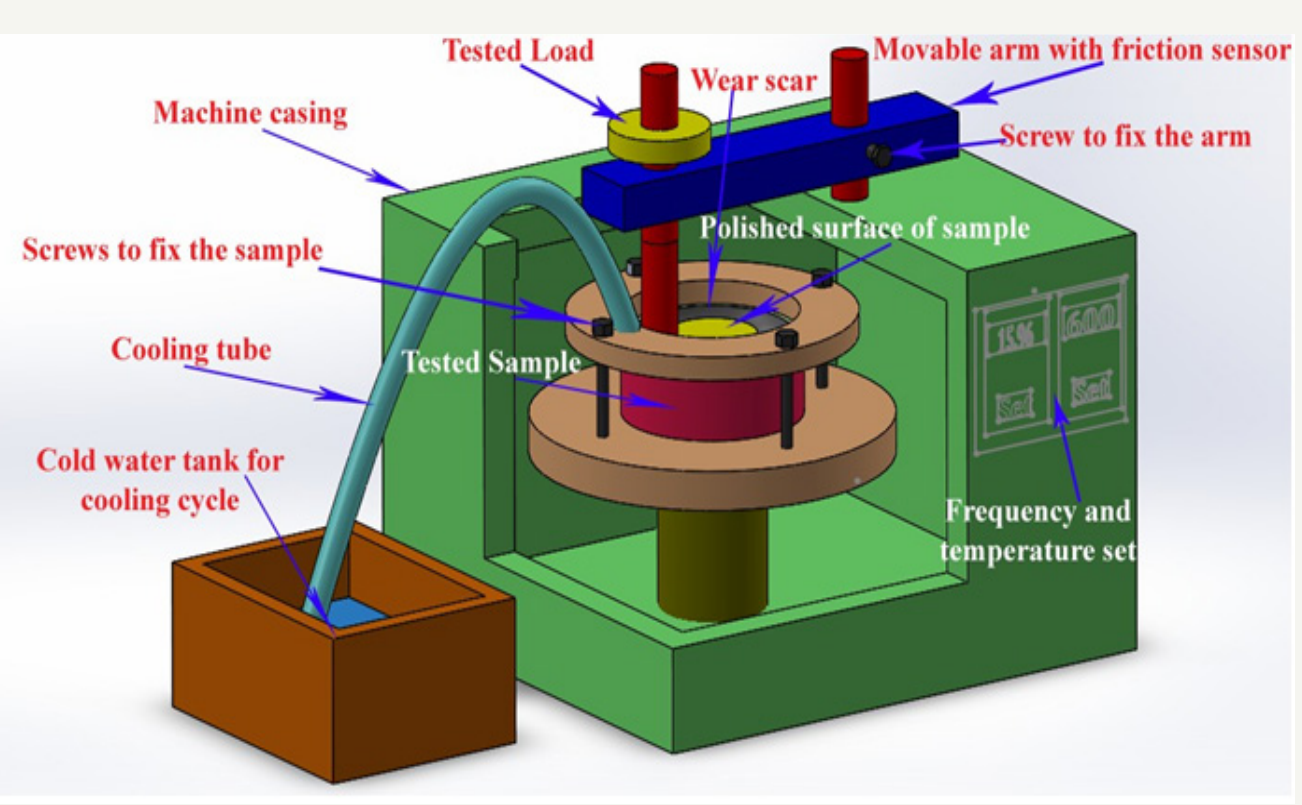

Figure 1: Schematic diagram of the HT-1000 pin-on-disk tribometer. 
The friction coefficients were automatically measured and recorded in real time by the computer system of the friction tester. A computer with special software is connected to the tribological machine to measure and record the friction coefficients of M50 specimens automatically and simultaneously all the time of the experiments. The formula $\mathrm{WR}=W v /(P \cdot D s)$, is used to calculate the wear rate, where WR is the wear rate in $\mathrm{mm}^{3} \mathrm{~N}^{-1} \mathrm{~m}^{-1}$, Wv is the wear volume taken from the specimen in $\mathrm{mm}^{3}, \mathrm{P}$ is the applied tested load in $\mathrm{N}$, and Ds is the sliding distance in $\mathrm{m}$. Besides, the wear volume is calculated by the formula $W v=A \cdot L$, where A represents the cross sectional area of the worn track, and $L$ is its perimeter. A surface profilometer is used to measure the cross-section profile of worn surface track. Finally, the final results for every experimented condition are obtained after repeating the test for three times to get reliable data. The worn surface morphologies of composites were characterized by EPMA.

\section{Microstructure Analyses}

Before conducting the tribological experiments, the XRD is used to scan and examine the surface of all samples with $\mathrm{Cu} \mathrm{Ka}$ radiation at $30 \mathrm{kV}$ and $40 \mathrm{~mA}$ at a scanning speed of $0.01^{\circ} \mathrm{s}^{-1}$ to recognize the phase composition. The microstructure of the contact worn surfaces and the cross sections of the worn surfaces were examined using electron probe microanalysis (EPMA, JAX-8230), field emission scanning electron microscope (FESEM, ZEISS ULTRA PLUS) and energy dispersive spectroscopy (EDS, Inca X-Act). Now, the investigated samples are ready to be analyzed in details to explore the different mechanisms of these specimens based on the output data of the above tests.

\section{Results and Discussion}

\section{Material characterization}

Table 1 lists the hardness of M50 after sintering. As aforementioned and explained in the above literature, Table 2 obtains generally speaking that M50 steel composites have a good hardness which is suitable for many applications. As illustrated from the table that the pure M50 has a hardness of $402.5 \pm 0.079$ HV1. Addition of WS2 to the M50 composites has improved remarkably the hardness as an important mechanical property. Using WS2 has improved the hardness of M50 composites to be $460.4 \pm 0.088$ HV1 with an augmentation percent of $14.4 \%$ as observed from Table 2.

XRD patterns of M50 samples are displayed in Figure 2. The main peaks of the pattern are obtained to have the main M50 components primarily which are oxides, marten site, and carbon phases as shown from the results of XRD. In addition, the phases of solid lubricants such as $\mathrm{WS}_{2}$ and $\mathrm{WO}_{3}$ are identified by the XRD test after adding WS2 to the main composite. Moreover, the new formation of carbide phases like $\mathrm{FeC}$ is detected also using the XRD test. This agrees the results indicating that during fabricating and sintering the M50 steel, a complex reaction as a function of the high tempering temperature occurs to produce some different types of carbide phases [22].

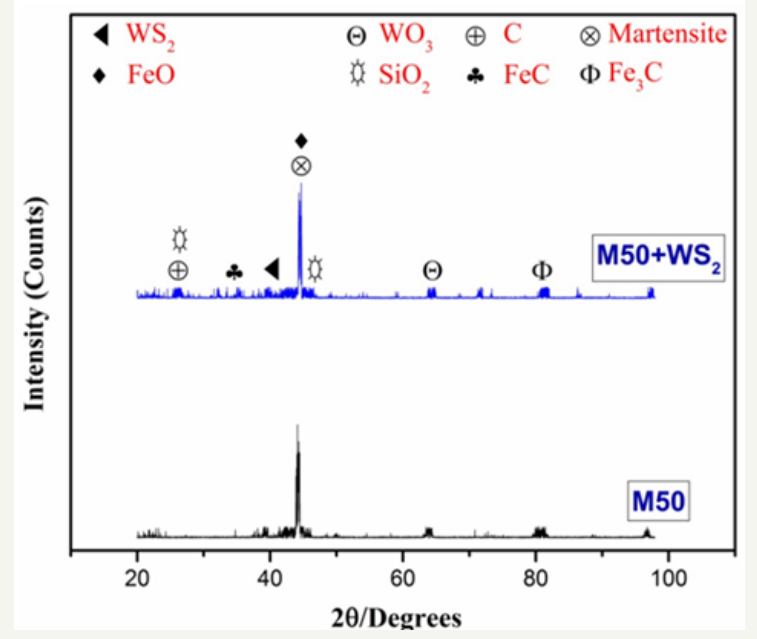

Figure 2: XRD patterns of sintered samples before friction test.
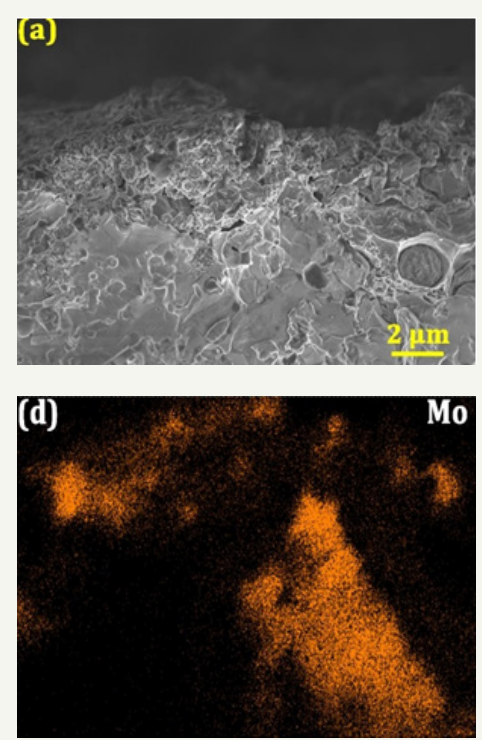
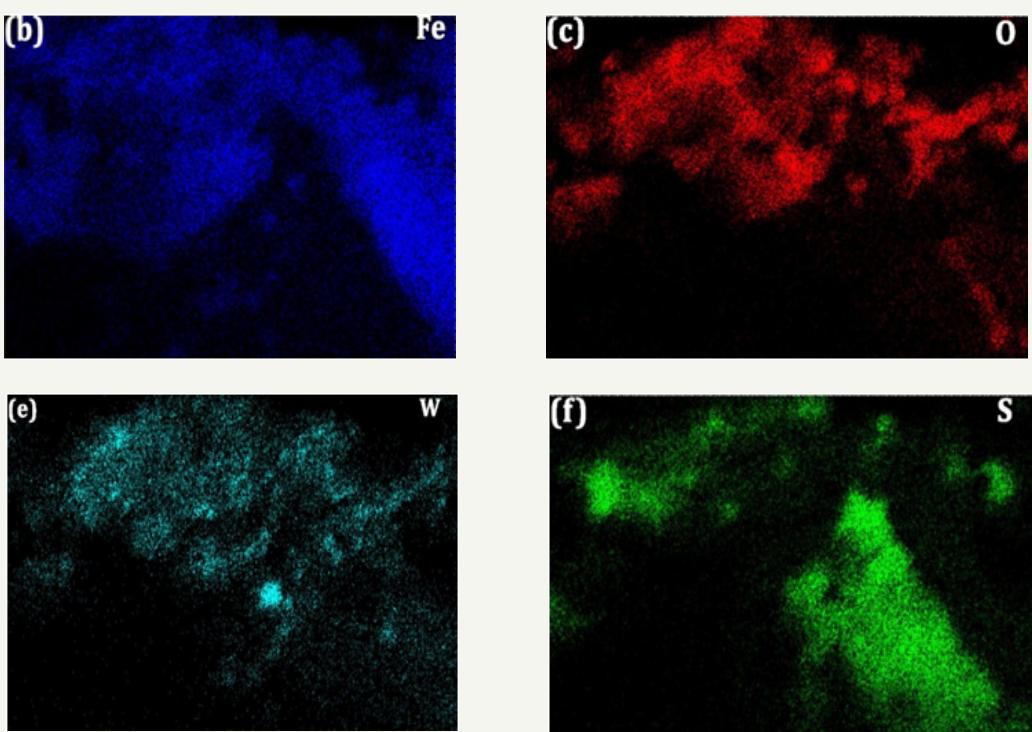

Figure 3: FESEM image (a) and Mapping (b-f) of cross-sectional wear scars of the MW at $800{ }^{\circ} \mathrm{C}$. 
The MW sample recorded lowest friction coefficient at $800{ }^{\circ} \mathrm{C}$, and hence the authors are interested in displaying and analyzing the characteristics of microstructure and distribution of elements of this sample, Figure 3. As analyzed by FESEM and EDS Mapping, the MW microstructure can be divided into two main homogeneous areas; light gray and gray. The light gray area has the lubricating surface tribo-film which mainly has the components of tungsten disulfide. While, the gray area has carbides and molbdenite plus the base element of M50 steel (Fe) as dominant phases.

\section{Tribological properties of M50 containing $\mathrm{WS}_{2}$ as solid lubricants}
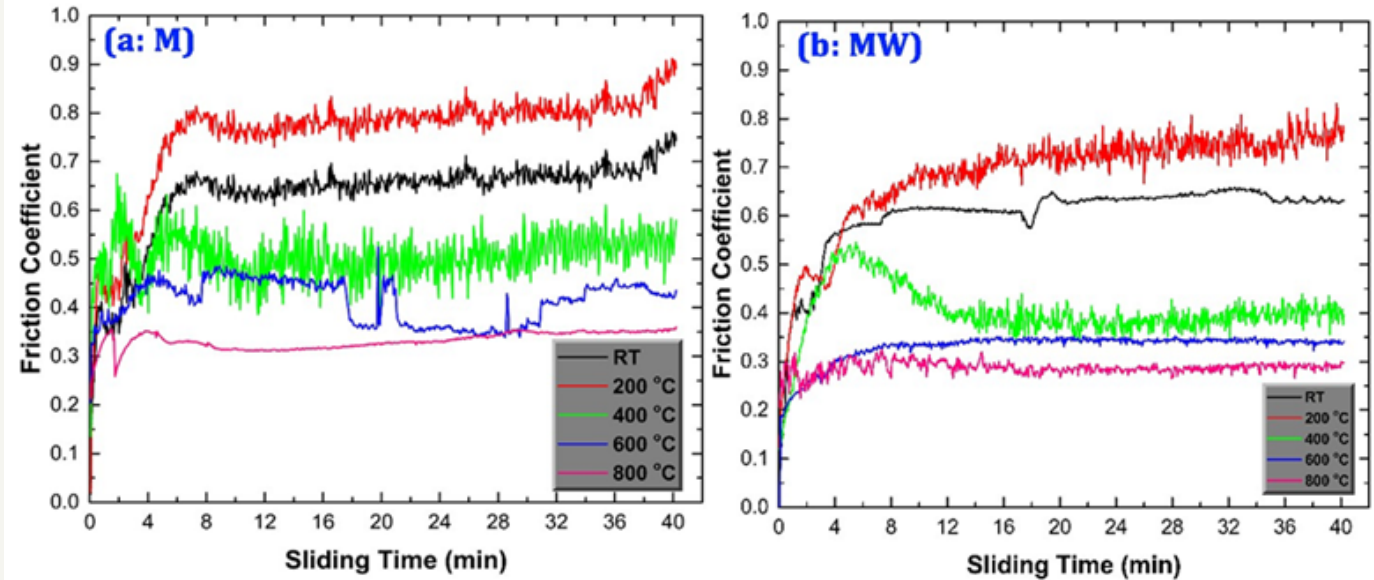

Figure 4: The instantaneous friction coefficients of samples at different temperatures.
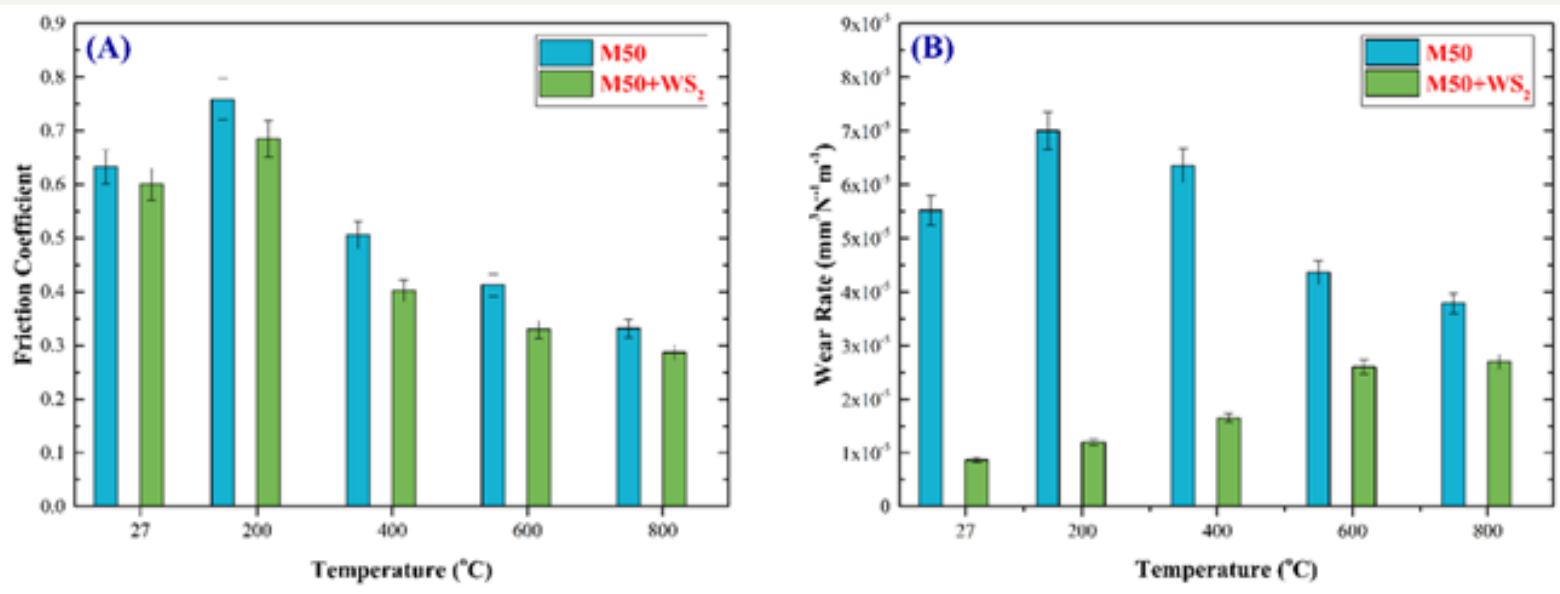

Figure 5: The average friction cofficients (a) and wear rates (b) of samples at different temperatures.

Friction and wear of specimens: The effects of using solid lubricants under different temperatures on the tribological behavior of M50 composites are investigated under constant load and velocity. The tribological behavior of any system is evaluated mainly based on the coefficient of friction. As a result, the steady friction coefficients and wear rates of M50 synthesized with $\mathrm{WS}_{2}$ solid lubricant under different temperatures are obtained in Figure 4 \& 5 Results revealed that the tribo-pairs have friction behaviors depended mainly on the operating temperature of the system. As observed from the figure, whatever the investigated temperature, the pure M50 steel has the greatest friction coefficients and wear rates as compared to the other explored samples, where the steady friction of this sample is changed from 0.63 to 0.33 when the temperature is changed from $\mathrm{RT}$ to $800{ }^{\circ} \mathrm{C}$, respectively. In addition, Figure 5 obtained that the friction coefficients, as well as the wear rates, have a similar behavior through all investigated conditions. Besides, the operating temperature and solid lubricant type are two parameters affecting significantly the friction coefficients and wear rates of M50 steel as revealed from Figure $4 \& 5$. As a result, the friction coefficient and wear rate are reduced dramatically by increasing the temperature. This result is obtained through the temperature range from RT to $800{ }^{\circ} \mathrm{C}$ except the temperature 200 ${ }^{\circ} \mathrm{C}$, where the friction coefficient of M50 composites recorded its highest values at $200^{\circ} \mathrm{C}$ even greater than that at RT. Based on the obtained results, the MW sample provided the best tribological behavior along the entire studied temperature range. The MW specimen presents the lowest friction coefficients at $800{ }^{\circ} \mathrm{C}$ as compared to the other composites as illustrated from Figure 5. The friction coefficient of MW is minimized from 0.69 at RT to 0.29 at $800{ }^{\circ} \mathrm{C}$, while the wear rate also is increased from $8.65 \mathrm{E}^{-6} \mathrm{~mm}^{3} \mathrm{~N}^{-}$ 
${ }^{1} \mathrm{~m}^{-1}$ to $2.7 \mathrm{E}^{-5} \mathrm{~mm}^{3} \mathrm{~N}^{-1} \mathrm{~m}^{-1}$ with increasing the temperature from RT to $800{ }^{\circ} \mathrm{C}$, respectively. This is due to that $\mathrm{WS}_{2}$ helps to enhance the tribological properties due to the formation of a lubricating tribofilm on the worn surface of MW. As a result, the friction coefficient is minimized especially at high temperatures [17-19,23]. To clearly clarify the temperature-adaptive action, the micrographs of worn surfaces of M, and MW after tests at different temperatures are investigated in the following.
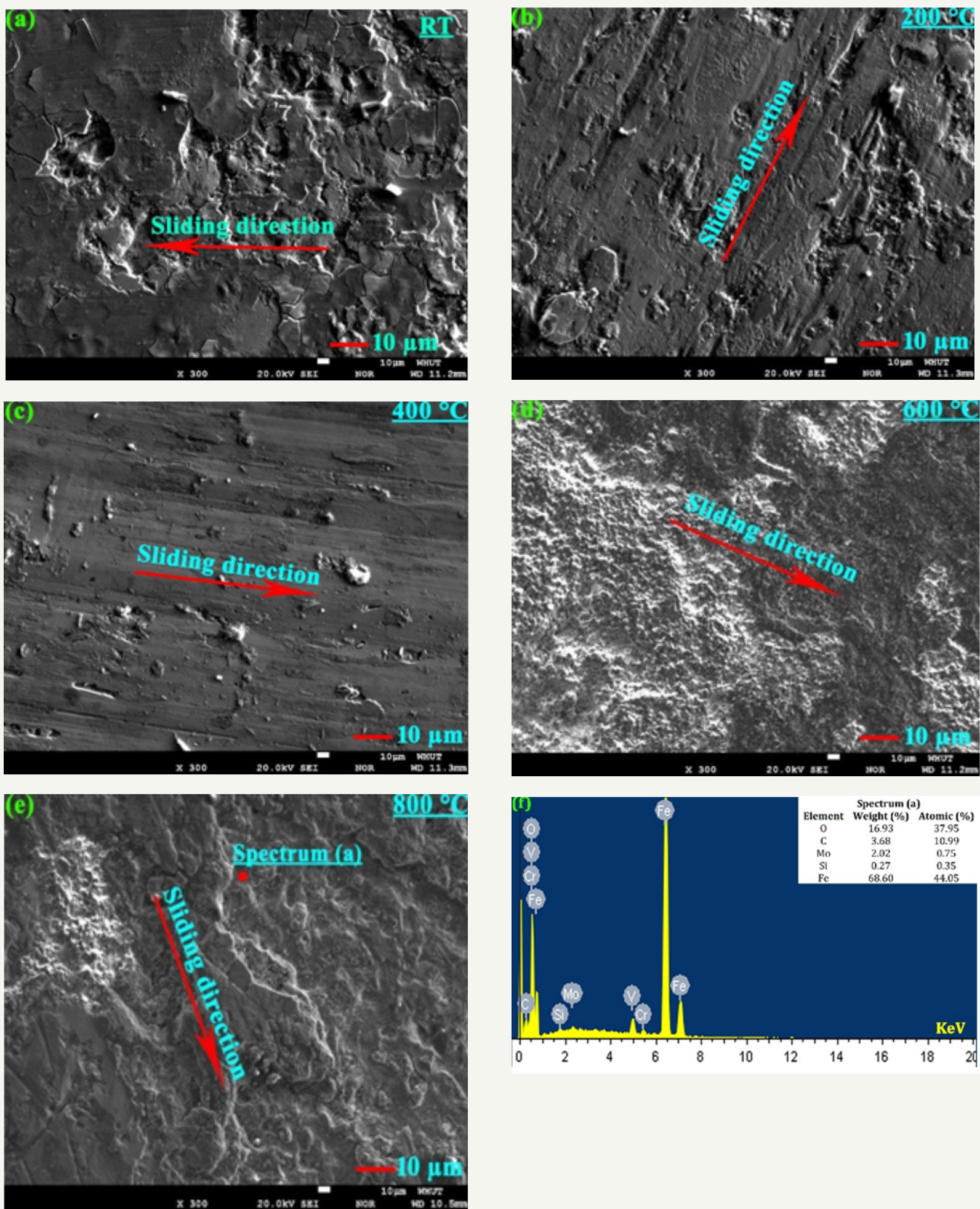

Figure 6: EPMA morphologies.

Figure 6a-6e: at different temperatures and EDS.

Figure 6f: at $800^{\circ} \mathrm{C}$ of the worn surfaces of $\mathrm{M}$ after wear testing. 
Morphologies of the pure M50 worn surfaces: The EPMA morphologies and EDS of the worn surfaces of pure M50 (M) after wear testing at different temperatures are shown in Figure 6a-6e It is distinctly seen that the morphology of worn surface of $M$ is different as a function of temperature. It can be observed from the figure that the M sample exhibits coarse worn surface with three types of dominant wears which are the abrasive wear resulting from the abrasive grits plowing over the worn surface leading to deep and long grooves. While, another type is the scuffing with adhesive junctions. Whereas, the last one is the delamination wear which is observed by the crack nucleation and propagation, and plastic deformation. So, a severe wear is obtained through the morphology characterization of the M worn surface. It agrees with the high friction coefficient and wear rate of $\mathrm{M}$. In addition, the wear debris oxide particles are found at some locations on the worn surface as examined by the EDS. Moreover, as is shown in Figure 6, such delamination pits and grooves are minimized and the worn surface is covered with somewhat discontinuous island-like films mainly consisting of oxides and molbdenite as suggested by EDS analysis as can be obtained from Figure $6 \mathrm{f}$ As a result, as the temperature progresses, the friction of $\mathrm{M}$ is minimized dramatically from 0.63 at RT to 0.33 at $800{ }^{\circ} \mathrm{C}$. This is due to forming the lubricating oxides and molbdenite which helps to improve the tribological behavior of $\mathrm{M}$ based on the working temperature as illustrated from Figure 6. An exception of this conclusion is noticed. The friction coefficient at $200{ }^{\circ} \mathrm{C}$ is 0.76 which is the greatest value among all investigated temperature. This is may be referred to forming the dis-lubricious silicon oxide as analyzed by EDS which works against the lubrication direction. Furthermore, the delamination pits at $800{ }^{\circ} \mathrm{C}$ are larger in comparison to that observed at lower temperatures. This is maybe referred to the adhering junctions affected by the high temperature to be the dominant wear type at $800{ }^{\circ} \mathrm{C}$. Comparing to the results of the other specimens, the $\mathrm{M}$ specimen exhibits greatest friction coefficient and high wear rate as drawn in Figure $4 \& 5$. This is generally due to the delamination pits and wear debris oxide particles on the worn surface resulting high abrasion. As aforementioned, the debris oxide particles may be referred to forming the abrasive silicon oxides on the worn surface of M [24].
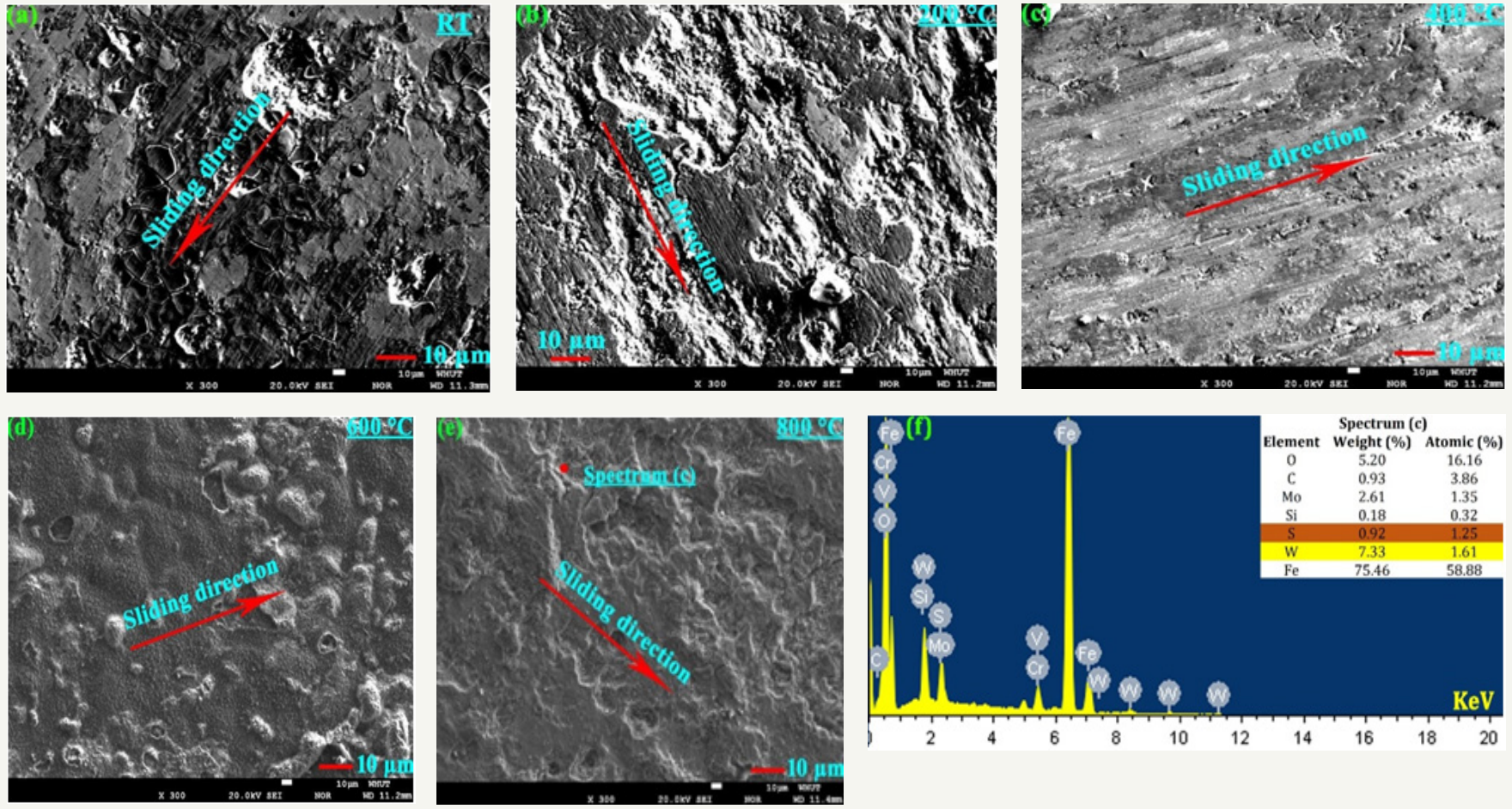

Figure 7: EPMA morphologies

Figure 7a-7d: at different temperatures.

Figure 7e: EDS.

Figure 7f: at $800{ }^{\circ} \mathrm{C}$ of the worn surfaces of $\mathrm{MW}$ after wear testing.

Morphologies of the MW worn surfaces: Other EPMA tests are performed to investigate the morphologies of the worn surfaces of MW (M50+10\%WS $)_{2}$ ) after wear tests under different temperatures as shown in Figure 7 It is seen that the morphology of worn surface of MW is different from that of $\mathrm{M}$. It is can be observed from Figure $7 \mathrm{a}-7 \mathrm{c}$ that from RT to $400{ }^{\circ} \mathrm{C}$, MW exhibits delaminated worn surface characterized by either crack nucleation and propagation or delaminated layers. Besides, the worst morphology of MW worn surface is observed at $200{ }^{\circ} \mathrm{C}$, which provides the worst friction coefficient (0.69) for this sample along the entire examined temperature range. This is due to the adhesive bonding between the real contact areas of the worn surfaces. In addition, the worn surface is enclosed with wear debris oxide particles at some locations. On contrast, at high temperatures from $600{ }^{\circ} \mathrm{C}$ to $800{ }^{\circ} \mathrm{C}$, it is distinctly revealed from Figure $7 \mathrm{~d} \& 7$ e that MW exhibits rough worn surface as compared to that of M due to 
the formed wear debris oxide particles. The worn surface of MW is covered with discontinuous island-like lubricating films mainly consisting of $\mathrm{WS}_{2}$ as suggested by EDS analyses, and severe grooves are no longer evident. The $\mathrm{WS}_{2}$-enrich films on the worn surface are responsible for the low wear rate and friction coefficient of MW due to the lamellar structure of $\mathrm{WS}_{2}$ at low temperatures as compared to $\mathrm{M}$ as evident from Figure 5. XRD and EDS analyses suggested that the compacted films are $\mathrm{WS}_{2}$-rich films at temperatures below 400 ${ }^{\circ} \mathrm{C}$, while the wear debris oxide particles strongly consist of $\mathrm{WO}_{3}$ at temperatures above $600^{\circ} \mathrm{C}$. This denotes that $\mathrm{WS}_{2}$ partially oxidizes into $\mathrm{WO}_{3}$ on the worn surface of MW at temperatures above 400 ${ }^{\circ} \mathrm{C}$, leading to decline of its lubricating characteristics as mentioned by [25]. Furthermore, at $600{ }^{\circ} \mathrm{C}$ and $800{ }^{\circ} \mathrm{C}, \mathrm{WS}_{2}$ is damaged by oxidization. It not only loses its lubricious effect, but also forms wear debris oxide particles which raise the friction coefficient. But, with increasing the temperature, some lubricating oxides, either from the substrate material itself or transferred from the counter face ceramic ball, and molybdenite are formed, and this is why the friction coefficient is decreased at the elevated temperatures. The morphology of $\mathrm{MW}$ at $800{ }^{\circ} \mathrm{C}$ provides more delamination worn surface than that of $600{ }^{\circ} \mathrm{C}$. Accordingly, the friction coefficients of MW at $800{ }^{\circ} \mathrm{C}$ is less than those at $600{ }^{\circ} \mathrm{C}$ as presented in Figure 5 As drawn in Figure 7f, the EDS analysis of the MW worn surface indicated that the worn surface is enriched by tungsten oxides such as W03, which increases the wear rate of MW, and some small $\mathrm{WS}_{2}$ at $800{ }^{\circ} \mathrm{C}$ [26]. Finally, the friction coefficient of MW is decreased from 0.60 to 0.29 with increasing the temperature from RT to $800{ }^{\circ} \mathrm{C}$, respectively. While, the specific wear rate of the same sample is increased from $8.65 \mathrm{E}^{-6} \mathrm{~mm}^{3} \mathrm{~N}^{-1} \mathrm{~m}^{-1}$ to $2.7 \mathrm{E}^{-5} \mathrm{~mm}^{3} \mathrm{~N}^{-1} \mathrm{~m}^{-1}$ when the temperature is increased from RT to $800{ }^{\circ} \mathrm{C}$, respectively. Regarding to the aforementioned results, it can be determined that $\mathrm{WS}_{2}$ is an effective solid lubricant for M50 within the temperature ranged from RT to $400{ }^{\circ} \mathrm{C}$, but loses its lubricious effect because of its oxidization at temperatures of 600 and $800{ }^{\circ} \mathrm{C}$. In addition, generally speaking, MW composites exhibit better tribological behaviors than that of pure M50.

Since MW provided the best tribological characteristics along the entire temperature range from RT to $800{ }^{\circ} \mathrm{C}$, the authors were interested to obtain more information about the lubrication mechanism of this sample. So, the cross-sectional wear scars of MW at $800^{\circ} \mathrm{C}$ are characterized by FESEM and EDS Mapping as illustrated in Figure 8. As observed in Figure 8, the FESEM morphology of cross-sectional taken vertical to the sliding direction supposed that the lubricating tribo-film enriched by $\mathrm{WS}_{2}$ with $150 \mathrm{~nm}$ thickness is found on the top of worn surface, which is responsible for reducing the friction coefficient of MW as drawn in Figure 5. The EDS test obtained in Figure 8b confirmed the aforementioned discussion about the lubricating effect of $\mathrm{WS}_{2}$. Moreover, what confirm the existence of the tribo-film is the high percentages of the additives of $\mathrm{WS}_{2}$ into the selected EDS area as obtained in Figure $8 \mathrm{~b}$. The lubrication tribo-film is directly contacted to the top worn surface of MW substrate. During sliding, MW exhibits lower friction coefficients due to the relative slippage either between the lubrication tribo-film and the substrate or between the lubrication tribo-film itself. As a result, the shearing forces are decreased significantly based on this lubrication mechanism, and hence, the friction forces are decreased.

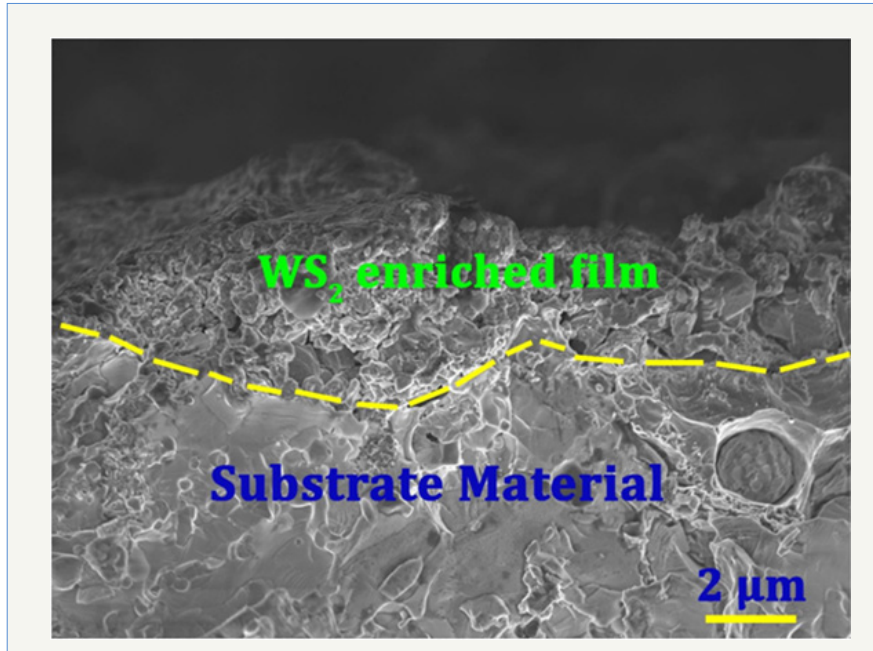

Figure 8: FESEM image of cross-sectional wear scars of the MW at $800{ }^{\circ} \mathrm{C}$.

Consequently, regarding to the aforementioned considerations, it can be supposed that the $\mathrm{WS}_{2}$ has actually the merit of lubricating action to produce low friction coefficient, and hence, desired and excellent tribological characteristics of MW are obtained along the wide range of temperature as compared to the pure M50.

\section{Conclusion}

In the current study, a novel comprehensive investigation is conducted to improve the tribological behaviors of M50 steel using WS2 solid lubricant under different temperatures

(RT, 200, 400, 600, and $800{ }^{\circ} \mathrm{C}$ ). On the basis of the results obtained above, the following main conclusions can be listed;

1. Using only single solid lubricant cannot provide the desired challengeable lubricating characteristics for M50 steel which is used in most of the modern technology systems such as aerospace and biomedical systems.

2. The friction coefficients of MW are decreased by $13.51 \%$ as compared to that of $\mathrm{M}$ at $800{ }^{\circ} \mathrm{C}$ due to formation of lubricating tribo-films on the worn surfaces.

3. The tribological properties of MW obtained the best results at $800{ }^{\circ} \mathrm{C}$, where the friction recorded its minimum value of 0.29 .

4. Generally speaking, the results in our study provide some suggestions to overcome the challenges when using M50 matrix composites as an MW in mechanical applications under extreme conditions.

\section{Acknowledgment}

This work was supported by the National Key Scientific Program-Nanoscience and Nanotechnology (no. 2011CB933700); the National Natural Science Foundation of China (no. 51210008); the authors also wish to gratefully thank the Material Research 
and Testing Center of Wuhan University of Technology for their assistance.

\section{References}

1. Holmberg K, Andersson P, Erdemir A (2012) Global energy consumption due to friction in passenger cars. Tribology International 47: 221-234.

2. Holmberg K, Matthews A (2009) Coatings tribology properties, mechanisms. Tribology and interface engineering series 56: 1-576.

3. Essa FA, Zhang Q, Huang X, Ibrahim AMM, Ali MKA, et al. (2017) Improved friction and wear of $\mathrm{M}_{50}$ steel composites incorporated with $\mathrm{ZnO}$ as a solid lubricant with different concentrations under different loads. J Mater Eng Perform 26: 4855-4866.

4. Essa F, Zhang $Q$ Huang $X$, Ibrahim AMM, Ali MKA, et al. (2017) Enhancing the tribological and mechanical properties of $\mathrm{M}_{50}$ steel using solid lubricants - A detailed review. Proc Inst Mech Eng Part J J Eng Tribol.

5. Bamberger EN, Zaretsky EV, Anderson WJ (1968) Fatigue life of $120 \mathrm{~mm}$ bore ball bearings at $600 \mathrm{deg} \mathrm{F}$ with fluorocarbon, polyphenyl ether, and synthetic paraffinic base lubricants. DTIC Document.

6. Shevchenko RP (1966) Lubricant requirements for high temperature bearings. SAE Technical Paper.

7. Essa FA, Zhang Q, Huang X, Ali MKA, Elagouz A, et al. (2017) Effects of $\mathrm{ZnO}$ and $\mathrm{MoS}_{2}$ solid lubricants on mechanical and tribological properties of $\mathrm{M}_{50}$-steel based composites at high temperatures - Experimental and simulation study. Tribol Lett 65(97).

8. Gerardi D, Trivedi H, Rosado L (1996) Evaluation of fatigue and wear characteristics of $\mathrm{M}_{50}$ steel using MIL- L-7808K. International Journal of Fatigue 18: 191-196.

9. Rosado L, Trivedi HK, Gerardi DT (1996) Evaluation of fatigue and wear characteristics of $\mathrm{M}_{50}$ steel using high temperature synthetic turbine engine lubricants-Part II. Wear 196: 133-140.

10. Trivedi HK, Gerardi DT, Rosado L (1995) Evaluation of fatigue and wear characteristics of $\mathrm{M}_{50}$ steel using synthetic ester turbine engine lubricants-Part 1. Wear 185: 111-117.

11. Essa FA, Zhang $Q$, Huang $X$ (2017) Investigation of the effects of mixtures of $\mathrm{WS}_{2}$ and $\mathrm{ZnO}$ solid lubricants on the sliding friction and wear of $\mathrm{M}_{50}$ steel against silicon nitride at elevated temperatures. Wear 374: 128141.

12. Childs T, Mimaroglu A (1993) Sliding friction and wear up to $600{ }^{\circ} \mathrm{C}$ of high speed steels and silicon nitrides for gas turbine bearings. Wear 162 : 890-896.
13. Sliney HE (1982) Solid lubricant materials for high temperatures-a review. Tribology International 15: 303-315.

14. Gupta S, Barsoum M (2011) On the tribology of the MAX phases and their composites during dry sliding: a review. Wear 271: 1878-1894.

15. Yang JF, Jiang Y, Hardell J, Prakash B, Fang QF (2013) Influence of service temperature on tribological characteristics of self-lubricant coatings: A review. Frontiers of Materials Science 7: 28-39.

16. Si PZ, Choi CJ, Lee JW, Geng DY, Zhang ZD (2007) Synthesis, structure and tribological performance of tungsten disulphide nanocomposites. Materials Science and Engineering 443: 167-171.

17. Donnet C, Erdemir A (2004) Solid lubricant coatings: recent developments and future trends. Tribology Letters 17: 389-397.

18. Prasad SV, McDevitt N, Zabinski J (2000) Tribology of tungsten disulfidenanocrystalline zinc oxide adaptive lubricant films from ambient to 500 C. Wear 237: 186-196.

19. Walck S, Zabinski J, McDevitt N, Bultman J (1997) Characterization of air-annealed, pulsed laser deposited $\mathrm{ZnO}-\mathrm{WS}_{2}$ solid film lubricants by transmission electron microscopy. Thin Solid Films 305: 130-143.

20. Standard A (2003) E92 2003 Standard test method for vickers hardness of metallic materials. West Conshohocken, PA: ASTM International.

21. ASFTA (2008) Standard Test Methods for Density of Compacted or Sintered Powder Metallurgy (PM) Products using Archimedes' Principle. ASTM B962-B1008.

22. Bridge JE, Maniar GN, Philip TV (1971) Carbides in M-50 high speed steel. Metallurgical and Materials Transactions B 2: 2209-2214.

23. Zhu S, Bi Q Niu M, Yang J, Liu W (2012) Tribological behavior of NiAl matrix composites with addition of oxides at high temperatures. Wear 274: 423-434.

24. Tong YX, Wang LQ Gu L (2010) Friction and wear behaviors of $\mathrm{Si}_{3} \mathrm{~N}_{4}$ sliding against $\mathrm{M}_{50}$ bearing steel in vacuum. Advanced Materials Research: Trans Tech Publ, pp. 1681-1684.

25. Xu S, Gao X, Hu M, Sun J, Jiang D, et al. (2014) Nanostructured $\mathrm{WS}_{2}-\mathrm{Ni}$ composite films for improved oxidation, resistance and tribological performance. Applied Surface Science 288: 15-25.

26. Xu Z, Zhang Q Zhai W (2015) Tribological properties of TiAl matrix selflubricating composites incorporated with tungsten disulfide and zinc oxide. RSC Advances 5: 45044-45052. 